\title{
Trách nhiệm xã hội và sự tiếp nối của các doanh nghiệp khởi nghiệp tại Việt Nam
}

\author{
Hồ Mạnh Toàn \\ SSHPA System \\ E-mail: toan@sshpa.com
}

Hà Nội, 27-11-2018

Những năm gần đây, 'khởi nghiệp' được truyền thông sử dụng dày đặc và dần trở' thành một từ khóa phổ biến. Thực tế, những người Việt Nam đầu tiên đã bắt đầu khởi nghiệp từ sau Đổi Mới và hầu hết đều phát triển thành các doanh nghiệp vừa và nhỏ [1]. Đến nay, Việt Nam hiện có khoảng hơn 500 nghìn doanh nghiệp vừa và nhỏ, và họ có những đóng góp rất lớn cho sự khởi sắc và phát triển của nền kinh tế.

Sự phát triển của khởi nghiệp tại Việt Nam có sự ảnh hưởng không nhỏ của các yếu tố địa lý hay văn hóa [1, 2]. Rất nhiều yếu tố văn hóa Việt Nam có ảnh hưởng sâu đến nhận thức của người Việt về kinh doanh như: hình ảnh phản diện của người kinh doanh trong các câu chuyện cổ, sự phân tầng xã hội 'sĩ-nông-công-thương' [1]. Bên cạnh đó, yếu tố địa lý cũng mang đến một vài sự khác biệt lí thú như nhóm những người khởi nghiệp ở miền Bắc có sự phụ thuộc vào năng lực sáng tạo trong khởi nghiệp nhiều hơn so với miền Nam hay miền Trung [2]. Rộng hơn nữa, những yếu tố này ảnh hưởng lớn đến các năng lực quan trọng trong khởi nghiệp như giá trị sáng tạo, sự quyết đoán của người khởi nghiệp, hay trách nhiệm xã hội.

Trách nhiệm xã hội doanh nghiệp (CSR) là một khái niệm được khá phổ biến thời gian gần đây. Tuy nhiên, bản chất của nó tại các nước đang phát triển vẫn còn nhiều câu hỏi. Một nghiên cứu năm 2017 [3] cho thấy các tín hiệu tích cực của mối quan hệ giữa trách nhiệm xã hội và hiệu quả tài chính của doanh nghiệp Việt Nam cũng như ảnh hưởng của các yếu tố quản trị doanh nghiệp. Bên cạnh đó, các đóng góp của CSR tới các hành vi vì môi trường của các nhân viên ngành khác sạn cũng đã được điều tra kĩ càng [4]. Ảnh hưởng của CSR đến các hành vi này là rất tích cực. Đồng thời, tinh thần kinh doanh của công ty cũng như sự gắn bó của nhân viên là rất quan trọng trong điều chỉnh sự ảnh hưởng này. Không chỉ trong ngành du lịch, CSR còn có những đóng góp quan trọng đến quản trị và chuyển giao tri thức trong dịch vụ $y$ tế $[5,6]$.

Một nghiên cứu khác mới đây [7] đã có lưu ý đến đặc trưng chính trị, kinh tế, văn hóa và xã hội của Việt Nam, và đưa ra một khung khái niệm phù hợp với ba yếu tố chính là: truyền thống, sự quản chế chính trị và tính hiện đại. Khung khái niệm này 
đã được kết nối hợp lí với các khái niệm văn hóa, tư tưởng đặc trưng của người Việt như Tam giáo đồng nguyên, chủ nghĩa Mác-Lênin, và tư tưởng Hồ Chí Minh.

Thực tế, sự gắn kết với xã hội chính là một yếu tố quan trọng trong thúc đẩy sự kiên định với doanh nghiệp của những người khởi nghiệp [2]. Có lẽ nhờ các giá trị xã hội đó mà số lượng các doanh nghiệp gia đình rất cao, phù hợp với các giá trị gia đình, các mối quan hệ nêu cao sự tin tưởng, chữ 'tín' trong Khổng giáo [1]. Các doanh nghiệp gia đình này phần lớn đều gặp khó khăn trong việc chuyển giao thế hệ. Vì thế nghiên cứu mới đây [8] đã cung cấp một mô hình quá trình học hỏi của người con cũng như vai trò của người cha trong đó. Người cha có vai trò rất quan trọng trong từng giai đoạn phát triển kiến thức kinh doanh của người con. Người cha là một hình

mẫu để người con noi theo khi còn nhỏ. Sau đó, cha trở thành người hỗ trợ trong quá trình học hỏi của con. Khi con bắt đầu tham gia vào việc kinh doanh của gia đình thì cha trở thành người người thầy. Cuối cùng, khi con trở thành một người lãnh đạo thì cha sẽ hỗ trợ và đưa ra lời khuyên khi cần thiết. Mô hình này có thể sẽ giúp các doanh nghiệp có kế hoạch phù hợp để quá trình chuyển giao được thành công.

Các tác giả cũng gợi ý chính phủ nên có sự hỗ trợ thông qua giảng dạy lí thuyết kinh doanh và khởi nghiệp, đồng thời các chương trình đào tạo cũng nên có sự tập trung vào quản lí doanh nghiệp gia đình. Điều này là rất quan trọng trong cải thiện chất lượng các chương trình giáo dục kinh doanh vì tại Việt Nam, các chương trình này mới chỉ xuất hiện tại Việt Nam trong vòng hơn 30 năm nay nhưng chất lượng giảng dạy vẫn bị đặt nhiều dấu hỏi, có độ lệch giữa điều sinh viên mong muốn và thực tế họ nhận được $[1,9]$.

\section{References:}

[1] Vuong, Q. H., \& Tran, T. D. (2009). The cultural dimensions of the Vietnamese private entrepreneurship. IUP Journal of Entrepreneurship Development, VI(34), 54-78.

[2] Vuong, Q. H. (2016). Impacts of geographical locations and sociocultural traits on the Vietnamese entrepreneurship. SpringPlus, 5, 1189, DOI: 10.1186/s40064016-2850-9.

[3] Kabir, R., \& Thai, H. M. (2017). Does corporate governance shape the relationship between corporate social responsibility and financial performance?. Pacific Accounting Review, 29(2), 227-258, D0I:10.1108/PAR-10-2016-0091.

[4] Luu, T. T. (2017). CSR and organizational citizenship behavior for the environment in hotel industry: The moderating roles of corporate entrepreneurship and employee attachment style. International Journal of Contemporary Hospitality Management, 29(11), 2867-2900, DOI:10.1108/IJCHM-02-2016-0080. 
[5] Luu, T. T. (2015). From clinical governance through CSR and knowledge sharing to clinical error control. Service Business, 9(4), 687-709, DOI:10.1007/s11628-014-0251-0.

[6] Luu, T. T. (2016). The chain effect from human resource-based clinical governance through emotional intelligence and CSR to knowledge sharing. Knowledge Management Research and Practice, 14(1), 126-143, DOI:10.1057/kmrp.2014.23.

[7] Nguyen, M., Bensemann, J., \& Kelly, S. (2018). Corporate social responsibility (CSR) in Vietnam: a conceptual framework. International Journal of Corporate Social Responsibility, 3(1), 9, DOI:10.1186/s40991-018-0032-5.

[8] Pham, T. T., Bell, R., \& Newton, D. (2018). The father's role in supporting the son's business knowledge development process in Vietnamese family businesses. Journal of Entrepreneurship in Emerging Economies, DOI:10.1108/IEEE-01-2018-0006.

[9] Ly, C. T. M., Vickers, M. H., \& Fernandez, S. (2015). Master of Business Administration (MBA) student outcomes in Vietnam: Graduate student insights from a qualitative study. Education+ Training, 57(1), 88-107, DOI:10.1108/ET-08-2013-0104. 